\title{
COMPORTAMENTO CLIMÁTICO DA REGIÃO METROPOLITANA DE FORTALEZA
}

\author{
dynamics of climate of Metropolitan Region of Fortaleza
}

\author{
Gledson Bezerra Magalhães* \\ Maria Elisa Zanella**
}

\begin{abstract}
Resumo
Analisou-se as características climáticas da Região Metropolitana de Fortaleza, a partir da espacialização da precipitação e temperatura do ar e da identificação dos sistemas atmosféricos atuantes entre os anos de 2001 a 2009. Para tanto, utilizou-se dados secundários provenientes das séries históricas de postos pluviométricos previamente selecionados e estimativas de temperatura do ar. $\mathrm{O}$ estudo apresenta tendências de chuva para os postos da RMF, a média climatológica dos mesmos e a espacialização da temperatura do ar e da precipitação a cada ano e nas suas respectivas quadras chuvosas, abordando as possíveis causas do comportamento pluviométrico e térmico na região. Verifica-se uma tendência crescente de chuvas para os postos analisados e um comportamento de chuvas heterogêneo espacial e temporalmente, porém similar a cada ano, tendo uma concentração de chuvas na porção nordeste de Caucaia, sudeste de Fortaleza e a sul de Eusébio. As estimativas de temperatura do ar apresentaram pouca variabilidade espacial, com diferença de $2^{\circ}$ entre a menor e a maior. Temperaturas mais elevadas foram verificadas nos meses de janeiro e dezembro, e as menores nos meses de junho e julho.
\end{abstract}

Palavras-chave: Temperatura do ar, Precipitação, Região Metropolitana de Fortaleza

\begin{abstract}
It was analyzed the climatic characteristics of the metropolitan area of Fortaleza, from thespatial distribution of precipitation and air temperature and the identification of activeweather systems between the years 2001 to 2009. For this purpose, it was used secondary data from the historical series of climatic stations previously selected and estimates of air temperature. The study presents trends of rain for the posts of RMF, the climatological average and spatial distribution of air temperature and precipitation each year in their respective rainy blocks, addressing the possible causes of the rainfall and thermal behavior in the region. There is a growing trend of rainfall for the posts analyzed and a behavior of rainfall spatial and temporal heterogeneity, but was similar each year, with a concentration of rain in the northeast portion of Caucaia, southeast of Fortaleza and south of Eusebio. The estimates of air temperature showed little spatial variability, with a difference of $2^{\circ}$ between the lowest and highest. Higher temperatures were observed during the months of January and December, and the lowest in the months of June and July.
\end{abstract}

Key words: Air temperature, Precipitation, Metropolitan Region of Fortaleza

\section{Resumen}

Se analizaron las características climáticas de la región metropolitana de Fortaleza, a partir de la distribución espacial de la precipitación y de la temperatura del aire y la identificación de los sistemas climáticos que actuaron entre los años 2001 a 2009. Con este fin, se utilizaron datos secundarios de la serie histórica de estaciones climáticas previamente seleccionados y las estimaciones de la temperatura del aire. El estudio presenta las tendencias de las precipitaciones para los cargos de la RMF, la normal climatológica y la misma distribución espacial de la temperatura del aire y las precipitaciones de cada año y las lluvias en sus respectivas temporada de lluvias, señalando las posibles causas de la lluvia y el comportamiento térmico de la región. Hay una tendencia creciente de las precipitaciones en las estaciones analizadas y el comportamiento de la lluvia espacial y temporalmente heterogéneos, pero con una concentración de lluvias en la zona noreste de Caucaia, en el sureste de Fortaleza y el sur de Eusebio a cada año. Las estimaciones de la temperatura del aire mostraron poca variabilidad espacial, con una diferencia de $2{ }^{\circ} \mathrm{C}$ entre el menor y mayor. Las temperaturas más altas se observaron en los meses de enero y diciembre y la menor en los meses de junio y julio.

Palabras clave: Temperatura del aire, Precipitación, Región Metropolitana de Fortaleza.

(*) Doutorando no Programa de Pós-Graduação em Geografia Universidade Federal do Ceará - Residência na Rua Lidia Petri Gonçalves, 1201 - CEP: 60.332-760- Fortaleza (CE) - Brasil, Tel.: (+ 55 85) 87110123 - gl_magalhaes@hotmail.com

(**) Prof ${ }^{a}$. Dr ${ }^{\mathrm{a}}$. da Pós-Graduação em Geografia da Universidade Federal do Ceará - Campus do Pici, Bl. 911, CEP: 60.445760, Fortaleza (CE) - Brasil, Tel/Fax: (+55 85) 33669855 / 33669864 - elisazv@terra.com.br 


\section{INTRODUÇÃO}

A atmosfera assim como a litosfera, a biosfera, a hidrosfera e a sociosfera constituem o arcabouço estrutural do planeta, e se fazem presentes, em contato dinâmico, na superfície terrestre, onde as trocas de energia e matéria são intermináveis. O clima gerido pela dinâmica atmosférica e pela interação desta com os outros invólucros que constituem o planeta é, como afirma MEDONÇA (1999: 31), "um dos importantes elementos formadores do ambiente planetário".

A sua interação com outras esferas da terra, entre os seus elementos, assim como a influência solar, geram diferentes climas no planeta, que se diferenciam de acordo com a variabilidade de seus elementos constituindo diferentes tipos de tempo atmosférico.

A compreensão das interações geradoras de clima e tempo distintos trazem informações fundamentais para diversos estudos que estejam vinculados ao clima, contribuindo para a gestão do território. A precipitação e a temperatura do ar são importantes elementos climáticos deste contexto. São constituintes essenciais para a definição do clima de uma região, além de exercerem forte influência na vida humana, podendo acarretar impactos negativos ou positivos em várias dimensões da sociedade. A cidade, reflexo da sociedade, com suas construções e funções urbanas também influencia na formação das condições atmosféricas e, portanto, do clima.

Nesse sentido este artigo traz em seu bojo uma análise da precipitação pluviométrica e da temperatura do ar na Região Metropolitana de Fortaleza (RMF), enfatizando o comportamento espaço-temporal desses elementos climáticos entre os anos de 2001 a 2009, subsidiando informações necessárias para se compreender a dinâmica dos mesmos. Também apresenta os principais sistemas atmosféricos atuantes na RMF, sistemas esses, basilares para a compreensão dos elementos climáticos do estudo.

\section{PROCEDIMENTOS METODOLÓGICOS}

O referencial teórico baseou-se os estudos de Monteiro (1976, 2003), que traz a proposta do Sistema Clima Urbano como metodologia de enfoque sistêmico do clima nas cidades, lançando as bases para se compreender os elementos atmosféricos em estreita relação com o ambiente urbano.

$\mathrm{Na}$ análise da precipitação, primeiramente realizou-se um levantamento e identificação de todos os postos pluviométricos existentes na RMF que apresentavam série histórica completa para o período em análise. Em seguida calcularam-se as tendências de chuva correspondentes ao período de análise para os 20 postos da RMF utilizados, gerando linhas de tendência linear e polinomial. A média climatológica de cada posto foi representada graficamente e as porcentagens de chuva foram feitas para a quadra chuvosa entre os anos de 2001 a 2009, justificada pela série histórica padronizada para todos os postos pluviométricos analisados.

Imagens de satélite fornecidas pela FUNCEME e INMET, e dados de temperatura da superfície do mar cedidas pelo Centro de Precisão de Tempo e Estudos Climáticos (CPTEC) para os anos de 2001 a 2009 permitiram traçar os meses onde normalmente ocorrem a atuação dos sistemas atmosféricos e os anos onde ocorreram a predominância dos eventos de El Niño, La Niña, assim como do Dipolo do Atlântico (Quadro 01).

Os dados relativos à precipitação pluviométrica, assim como a localização dos postos pluviométricos foram adquiridos junto a Fundação Cearense de Meteorologia e Recursos Hídricos (FUNCEME). Após a coleta de dados houve o tratamento geoestatístico dos dados coletados, onde foram organizados e analisados no ambiente computacional Microsoft Excel, objetivando a padronização do banco de dados adquirido. Em seguida foram espacializados anual e sazonalmente no software Surfer 8.0, através do método de interpolação 'krigin' ou 'krigeagem'. Para as espacializações utilizou-se uma base cartográfica da RMF adaptada da base cartográfica do Ceará, fornecida pelo IPECE (2009).

No estudo das características térmicas na RMF realizou-se estimativas de temperatura do ar através do programa computacional Celina, onde baseado nas regiões climáticas do Ceará adotadas 
pela FUNCEME, e utilizando-se o método estatístico regressão linear múltipla estimou-se a média mensal de temperatura do ar, considerando as informações (latitude, longitude e altitude) dos postos pluviométricos utilizados na pesquisa. Optou-se por esses 'pontos' na tentativa de estabelecer um padrão comum de informações espaciais entre os elementos climáticos analisados. Não se considerou viável utilizar os dados de temperatura do ar das Plataformas de Coleta de Dados (PCD's) ou das estações meteorológicas visto que dentro a RMF só existe uma Estação Meteorológica (Campus do Pici) em funcionamento e abarcando a escala temporal da pesquisa, logo os dados dessa Estação Meteorológica não seriam significativamente representativos para toda a RMF.

\section{CARACTERÍSTICAS CLIMÁTICAS DA REGIÃO METROPOLITANA DE FORTALEZA (RMF)}

A característica climática da RMF é representada pela sazonalidade da precipitação e por elevadas temperaturas o ano todo. A sua localização territorial e latitudinal próximo ao Equador (paralelos de $3^{\circ}$ a $4^{\circ} \mathrm{Sul}$ ), favorece uma intensa insolação o ano todo, proporcionando elevadas temperaturas com fracas amplitudes térmicas (características de climas tropicais quentes), e a atuação de diferentes sistemas atmosféricos estabelecendo a sazonalidade da precipitação. Ressalta-se que a RMF se encontra próximo ao oceano sofrendo influência marítima e conseqüentemente temperaturas mais amenas do que outras regiões do interior do Estado.

A localização geográfica da RMF permite que esta seja influenciada pelas massas de ar equatoriais e tropicais, que associado à configuração geográfica, altitude e forma de relevo, maritimidade/ continentalidade e extensão territorial, definem o clima da região como tropical equatorial com até 6 meses secos, de acordo com Mendonça e Danni-Oliveira (2007) que definiram cinco principais tipos climáticos do país e seus diferentes subtipos.

A altitude do relevo e a latitude da RMF constituem-se nos dois principais fatores geográficos (estáticos) da caracterização climática desta região. O adensamento urbano, a distribuição de terras, águas e vegetação da superfície associam-se a estes fatores na definição climática da RMF. A baixa altitude dos relevos não ultrapassando 200 metros na maior parte da RMF com exceção dos maciços residuais que oscilam entre 400 a $700 \mathrm{~m}$ favorece a entrada dos sistemas atmosféricos provenientes do oceano (COLARES, 1996). As serras de Maranguape e Pacatuba constituem barreiras topográficas capazes de gerar chuvas orográficas apenas em contatos com nuvens de baixa altitude.

As atividades humanas que, sobretudo a partir de meados do século XX, ocasionaram profundas mudanças na paisagem da região metropolitana através do desmatamento, agricultura, urbanização e industrialização repercutiram diretamente na configuração climática em escala local. Estudos como o de Xavier (1996), Maia et al (1996), Pétalas (2000) comprovam um aumento da temperatura do ar em Fortaleza desde a década de 70. O estudo de Moura (2008) identificou ilhas de calor em Fortaleza com valores superiores a $5^{\circ} \mathrm{C}$, em partes da cidade onde se verifica um maior adensamento urbano e intenso fluxo de pessoas e veículos.

Segundo Brandão (1998), a temperatura média anual nas áreas litorâneas fica entre $26^{\circ} \mathrm{C}$ e $27^{\circ}$ $\mathrm{C}$ com máximas situando-se entre $31^{\circ} \mathrm{C}$ e $32^{\circ} \mathrm{C}$. A média anual das áreas serranas, como as serras de Maranguape, Aratanha/Pacatuba, tornam-se mais amenas e decaem para $25^{\circ} \mathrm{C}$, atingindo valores em torno de $22^{\circ} \mathrm{C}$. Nas áreas interiores, a média atinge o patamar de $28^{\circ} \mathrm{C}$, enquanto a média das máximas fica em torno de $33^{\circ} \mathrm{C}$ a $34^{\circ} \mathrm{C}$.

Zanella (2005) afirma que as chuvas se concentram, principalmente nos meses de fevereiro/ março/abril/maio, denominado quadra chuvosa, quando o Estado fica sob a influência da Zona de Convergência Intertropical (ZCIT), principal sistema atmosférico causador de precipitação. Os Vórtices Ciclônicos de Ar Superior (VCAS), as Linhas de Instabilidade, os Complexos Convectivos de Mesoescala (CCMs) e as Ondas de Leste, são sistemas sinóticos que também geram chuvas para a região.

A quantidade de precipitação também é influenciada pela atuação dos fenômenos El Niño e La Niña, assim como pela temperatura da superfície do mar do oceano Atlântico Tropical norte e sul (Dipolos do Atlântico Tropical). Estes modificam a circulação atmosférica de grande escala 
causando alterações nos totais pluviométricos do Estado do Ceará, e mantendo influências sobre os sistemas atmosféricos locais.

Os estudos de Aragão (1996, 1998), Moura et al (2000) e Ferreira et al (2004), verificaram que a influência concomitante dos oceanos Pacífico e Atlântico no Nordeste brasileiro ocorrem de dois modos principais: os anos de La Niña e Dipolo Negativo (Atlântico Sul quente e Atlântico Norte frio) correspondem a anos com excesso de chuva; já os anos com El Niño e Dipolo Positivo (Atlântico Sul frio e Atlântico Norte quente) correspondem a episódios de seca.

Em anos neutros, ou seja, onde não se têm a atuação da La Niña nem El Niño, o Dipolo do Atlântico comanda em grande escala as precipitações na RMF, principalmente na quadra chuvosa, influenciando diretamente na posição da ZCIT. Nobre e Shukla (1996) apontam que tal padrão de anomalias de TSM possibilita a ocorrência de gradientes meridionais de anomalias de TSM, influenciando bastante na posição latitudinal da ZCIT, e conseqüentemente alterando a distribuição sazonal de precipitação pluviométrica sobre o Atlântico Equatorial, parte norte do Nordeste do Brasil, até a parte central da Amazônia. Cabe salientar que pode ocorrer a atuação dos fenômenos vinculados ao oceano Pacífico e Atlântico com conseqüências inversas, ou seja, enquanto um oceano gera condições favoráveis à precipitação na RMF, o outro oceano gera condições desfavoráveis. Nesses casos as condições favoráveis ou não à precipitação estarão vinculadas à intensidade de atuação de cada fenômeno.

\section{ANÁLISE DA PRECIPITAÇÃO PLUVIOMÉTRICA}

Os primeiros semestres de cada ano, particularmente os meses de fevereiro, março, abril e maio concentraram os maiores números de sistemas atmosféricos, em especial a ZCIT, principal sistema causador de precipitação na RMF. Foi também nesse período onde se verificou os maiores totais pluviométricos.

No período de 2001 a 2009 houve uma maior atuação do El Niño, onde em sete destes anos configurou-se o fenômeno, sendo cinco anos de El Nino fraco e dois anos de El Niño moderado. Em relação à La Niña, foi registrado um ano de La Niña fraca, dois anos de La Niña moderada e dois anos de La Niña forte (Quadro 1). Três anos apresentaram a atuação da La Niña e El Niño, na quadra chuvosa.

Referente ao Dipolo do Atlântico, somente um ano ocorreu neutralidade, cinco anos apresentaram Dipolo negativo e cinco anos apresentaram Dipolo positivo, sendo que dois anos tiveram Dipolo negativo e positivo na quadra chuvosa. Vale ressaltar que não existe um padrão de comportamento e de periodicidade para os eventos oceânico-atmosféricos de mesoescala, podendo ocorrer qualquer um deles em períodos do ano não específicos e com duração indeterminada.

Quadro 1 - Anos de atuação dos fenômenos oceânico-atmosféricos

\begin{tabular}{|c|c|c|}
\hline ANOS & EL NIÑO - LA NIÑA - ANO NEUTRO & DIPOLO DO ATLÂNTICO \\
\hline 2001 & La Niña moderada & Neutro \\
\hline 2002 & El Niño moderado & Negativo (favorável) \\
\hline 2003 & E1 Niño moderado & Negativo (favorável) \\
\hline 2004 & El Niño fraco & Positivo (desfavorável) \\
\hline 2005 & El Niño fraco & Positivo (desfavorável) \\
\hline 2006 & $\begin{array}{l}\text { La Ninã fraca no inicio da quadra chuvosa. No final da quadra } \\
\text { chuvosa se configurou El Nino fraco }\end{array}$ & $\begin{array}{l}\text { Positivo } \\
\text { (desfavorável) }\end{array}$ \\
\hline 2007 & $\begin{array}{l}\text { La Niña forte no início da quadra chuvosa. No final da quadra } \\
\text { chuvosa se configurou El Niño fraco. }\end{array}$ & $\begin{array}{l}\text { Positivo no início da quadra chuvosa; no final da quadra } \\
\text { chuvosa se configuro negativo. }\end{array}$ \\
\hline 2008 & La Niña forte & $\begin{array}{l}\text { Negativo no início da quadra chuvosa; no final da quadra } \\
\text { chuvosa se configurou positivo. }\end{array}$ \\
\hline 2009 & $\begin{array}{l}\text { El Niño fraco no início da quadra chuvosa. No final da quadra } \\
\text { chuvosa se configurou La Niña moderada. }\end{array}$ & Negativo (favorável) \\
\hline
\end{tabular}

Fonte: FUNCEME 
Com base nos limites inferior e superior definidos para cada região pluviométrica homogênea contidos no sistema de classificação pluviométrico elaborado por Xavier (2001), foi possível delimitar, dentro do período de 2001 a 2009, os anos muito chuvosos, chuvosos, normais/habituais, secos e muito secos, para cada município da RMF dentro de suas respectivas regiões pluviométricas homogêneas (Quadro 2), e cruzá-los com os anos de El Niño, La Niña e Dipolos do Atlântico.

Nos quadros 1 e 2 pode-se observar a relação existente entre os sistemas oceânico-atmosféricos de mesoescala e a quantidade de precipitação na quadra chuvosa. Todavia, outros fatores em escala local também influenciam na quantidade de precipitação, fazendo com que a atuação e conseqüências do El Niño, La Niña e Dipolo do Atlântico sejam minimizadas ou não se evidenciem de forma tão nítida.

Em 2001 a configuração de La Ninã moderada e Dipolo do Atlântico neutro formaram condições de mesoescala favoráveis a precipitação, todavia excetuando-se os postos pluviométricos mais próximos do litoral, os restantes apresentaram uma tipologia climática de ano habitual a muito seco, com 12 postos marcando tipologias de seco a muito seco (Quadro 02).

Nos anos de 2002 e 2003 apesar de ter ocorrido El Niño, o Dipolo do Atlântico estava favorável à precipitação, ocasionando maior quantidade de chuva do que no ano de 2001, onde se configurou La Niña e Dipolo neutro. Os anos de 2004 e 2005 apresentaram as menores precipitações dentro da série estudada. Nesses anos a RMF estava sobre a influência de El Niño e Dipolo do Atlântico positivo, configurando-se condições desfavoráveis a precipitação (Quadro 01). Em 2006, a atuação da La Niña no início da quadra chuvosa garantiu maiores precipitações que as dos dois anos anteriores. No ano de 2007 ocorreu a atuação da La Niña com o Dipolo positivo no início da quadra chuvosa e El Niño com Dipolo negativo no final da quadra chuvosa, o que explica a baixa precipitação na maioria dos postos pluviométricos estudados.

Para 2008, a atuação do Dipolo negativo associado a La Niña garantiu a precipitação no início da quadra chuvosa, entretanto a constituição de Dipolo positivo na maior parte do período chuvoso inibiu as chuvas nessa região, devido ao deslocamento da ZCIT para o norte da linha do equador, gerando um comportamento temporal da precipitação típico do Estado. No ano de 2009, apesar de no início da quadra chuvosa se configurar El Niño, o Dipolo negativo garantiu o deslocamento da ZCIT para o sul da linha do equador favorecendo a ocorrência chuvas na RMF, fato este intensificado com a atuação da La Niña no final da quadra chuvosa.

No quadro 2 é possível perceber uma variabilidade espacial entre os postos pluviométricos a cada ano, isso é uma característica da região semi-árida brasileira, onde se percebe diferenças pluviométricas significativas entre os postos, sendo os postos mais próximos do oceano os que apresentam maiores totais pluviométricos, devido aos sistemas atmosféricos causadores de chuva atuantes no litoral, como as linhas de instabilidade, os sistemas de brisas e as ondas de leste.

Observando os totais anuais de chuva de cada posto pluviométrico para o período estudado, notou-se uma variação pluviométrica, entre os postos de maior e menor total de precipitação, de $1419 \mathrm{~mm}$ para o ano mais chuvoso (2009) sendo a maior concentração no posto Cascavel-Cascavel $(2533 \mathrm{~mm})$ e a menor no posto Caucaia-Bom Princípio $(1114 \mathrm{~mm})$, enquanto que o ano mais seco (2005) teve uma variação de $651 \mathrm{~mm}$, registrando o maior total de precipitação no posto FortalezaPici (1095 mm) e o menor no posto Maranguape-Comunidade Lemos (444 mm). A maior variação ocorreu no ano de 2003 (1530,8mm), o segundo ano mais chuvoso, sendo que os postos com maior e menor registro do total anual de precipitação foram respectivamente os postos de Caucaia-Caucaia $(2277,6 \mathrm{~mm})$ e Cascavel-Cristais (746,8 mm). A menor variação corresponde ao ano mais seco. Esse comportamento se repetiu ao analisar-se a quadra chuvosa. Quando observado somente a quadra chuvosa, o ano de 2009 apresentou uma variação de 705,4mm entre os postos com maior e menor registro do total de precipitação, enquanto o de 2005 teve uma variação de $477 \mathrm{~mm}$ entre os postos.

Relativo às tendências, com exceção dos postos Caucaia-Caucaia, Eusébio-Eusébio e Fortaleza- 
-Água Fria que não apresentaram variação significativa. Todos os postos apresentaram tendência de aumento de chuvas. Cabe ressaltar que essas tendências não permitem afirmar que ocorreu tendências similares em anos anteriores ou que ocorrerão tendências similares nos anos seguintes, visto o dinamismo atmosférico e o período temporal curto na análise. Todavia elas permitem uma visualização genérica do comportamento pluvial dentro dos anos analisados, permitindo mensurar estatisticamente a evolução da chuva dentro do período.

Quadro 2 - Total de precipitação na quadra chuvosa e classificação chuvosa

\begin{tabular}{|l|r|r|r|r|r|r|r|r|r|}
\hline \multicolumn{1}{|c|}{ POSTOS/ANO } & $\mathbf{2 0 0 1}$ & $\mathbf{2 0 0 2}$ & $\mathbf{2 0 0 3}$ & $\mathbf{2 0 0 4}$ & $\mathbf{2 0 0 5}$ & $\mathbf{2 0 0 6}$ & \multicolumn{2}{c|}{$\mathbf{2 0 0 7}$} & \multicolumn{2}{c|}{$\mathbf{2 0 0 8}$} & \multicolumn{2}{c|}{$\mathbf{2 0 0 9}$} \\
\hline Aquiraz - Aquiraz & 1229,8 & 1214,9 & 1449,3 & 957,2 & 697,4 & 1195,6 & 1028,1 & 1182,6 & 1620,4 \\
\hline Cascavel - Cascavel & 842,7 & 1239 & 1504,4 & 838 & 642,5 & 1252,9 & 1099,3 & 1002 & 2041 \\
\hline Cascavel - Cristais & 493,8 & 599 & 602,4 & 447,7 & 548,4 & 716,7 & 623,8 & 593,2 & 1046,5 \\
\hline Caucaia - Bom Princípio & 428 & 495 & 784,4 & 490 & 648 & 837,2 & 577 & 648 & 915 \\
\hline Caucaia - Caucaia & 1122,5 & 1063 & 1862,8 & 948,4 & 757,4 & 949,6 & 976,4 & 1053,9 & 1530,6 \\
\hline Chorozinho - Chorozinho & 509 & 838 & 820 & 634 & 701 & 794 & 609,6 & 631,2 & 1233 \\
\hline Eusébio - Eusébio & 1259 & 1166 & 1572 & 1037 & 752 & 1285 & 1153 & 962 & 1539 \\
\hline Fortaleza - Água Fria & 1149,7 & 1219,8 & 1664,1 & 1109,4 & 631,8 & 1135,4 & 1134,2 & 1010 & 1530,4 \\
\hline Fortaleza - Pici & 920,8 & 1034,7 & 1654,5 & 952,7 & 880 & 1082,5 & 1022,9 & 1038,3 & 1569,1 \\
\hline Horizonte & 756,6 & 964,6 & 980,9 & 613,1 & 449,1 & 789,5 & 627,9 & 825,5 & 1522,7 \\
\hline Itaitinga & 887 & 997 & 1125 & 749 & 722 & 1064 & 827 & 884 & 1693 \\
\hline Maracanaú - Maracanaú & 651,4 & 938,2 & 1313,2 & 856 & 569,6 & 895,2 & 863,4 & 996,2 & 1541,5 \\
\hline Maranguape - Comunidade Lemos & 415 & 684 & 753 & 444 & 403 & 800 & 591 & 460 & 950 \\
\hline Maranguape - Jubaia & 492,5 & 1042,2 & 845,7 & 766,4 & 607,5 & 872,4 & 652 & 705,1 & 1017,9 \\
\hline Maranguape - Lagoa Juvenal & 430,3 & 776,1 & 753,3 & 561,5 & 549,7 & 687 & 542 & 654,5 & 1127 \\
\hline Maranguape - Tanques & 539,8 & 801 & 901 & 641,8 & 612 & 898 & 653 & 879 & 1096 \\
\hline Pacajus - Pacajus & 731,2 & 905,1 & 1055,9 & 548,4 & 492,4 & 955,4 & 690,9 & 795,9 & 1492,7 \\
\hline Pacajus - Itaipaba & 709,6 & 909 & 985,4 & 542,6 & 593,2 & 816,8 & 736,4 & 780 & 1203 \\
\hline Pindoretama - Pindoretama & 969 & 1110 & 1296 & 781 & 825 & 1249 & 906 & 1050 & 1865 \\
\hline São Gonçalo - São Gonçalo & 638,1 & 720,2 & 1267,9 & 567 & 509,6 & 889,4 & 817,1 & 735,4 & 1434,8 \\
\hline
\end{tabular}

\begin{tabular}{|llllll|}
\hline Legenda: & Muito seco & Seco & Normal/habitual & Chuvoso & Muito chuvoso \\
\hline
\end{tabular}

Fonte de dados: FUNCEME

No que concerne à média climatológica, a figura 1 apresenta a média climatológica organizada de forma crescente para cada posto pluviométrico da RMF. A variabilidade espacial é marcada com valores oscilando entre 1673,2 $\mathrm{mm}$ no posto Eusébio - Eusébio e 787,7 mm no posto Maranguape - Comunidade Lemos, tendo uma variação espacial de $885,5 \mathrm{~mm}$ para os extremos.

Os municípios de Eusébio, Fortaleza, Aquiraz, Cascavel e a porção noroeste e norte de Caucaia apresentaram médias pluviométricas superiores a $1500 \mathrm{~mm}$. Pindoretama, Itaitinga, Pacajus, São Gonçalo do Amarante, Horizonte, Maracanaú e o setor sudoeste de Maranguape apresentaram médias entre 1000 e $1500 \mathrm{~mm}$, enquanto que os municípios de Cascavel, Chorozinho, parte sul de Caucaia e a porção sul de Maranguape apresentaram média climatológica inferior a $1000 \mathrm{~mm}$. Cascavel, devido a sua extensão latitudinal, foi o município com maior variação espacial de precipitação da média climatológica $(689 \mathrm{~mm})$.

Na figura 2 constam às isoietas referentes à média climatológica. Observa-se que as chuvas se apresentam heterogêneas espacialmente, com valores de aproximadamente $950 \mathrm{~mm}$ ao sul da RMF. No litoral leste se estendendo até Fortaleza constatou-se valores superiores a $1400 \mathrm{~mm}$. Na porção litorânea verifica-se uma média maior de precipitação, haja vista a proximidade com o oceano, favorecendo a atuação de sistemas atmosféricas atuantes neste setor (frentes de brisas, linhas de instabilidade e ondas de leste). 
Observa-se uma área com concentração de precipitação localizada a sudeste do Município de Fortaleza e ao sul de Eusébio. Esses setores com maior pluviosidade justificam-se pela posição geográfica favorecida da área, recebendo os sistemas atmosféricos oriundos do oceano. Neles verifica-se uma variação significativa de chuvas (isoietas mais próximas), tendo o posto de Eusébio como o limite de chuvas com a média de $1450 \mathrm{~mm}$ anuais e o extremo da área onde ocorre mais precipitação no sentido litoral-continente. A configuração plana do relevo permite que os sistemas atmosféricos vindos do oceano, adentrem o continente gerando chuvas ao sul de Eusébio e leste-sudeste de Fortaleza. Na porção leste de Fortaleza, registraram-se os maiores totais de precipitação para o referido município, onde diminui gradativamente ao se afastar do litoral no sentido continente. O estudo de Xavier (2001), calculando as normais pluviométricas em termos das médias de chuva para a quadra chuvosa entre os anos de 1964 a 1996, utilizando-se de 93 postos pluviométricos do Estado, verificou que as maiores normais para e região pluviométrica homogênea Litoral de Fortaleza estavam nos postos de Fortaleza e Aquiraz, haja vista que o posto do município de Eusébio ainda não estava em funcionamento. $O$ que mostra que a concentração de chuva nesse setor é uma característica pluviométrica da RMF. De forma geral as chuvas se concentraram principalmente nos litorais de Aquiraz, Eusébio, Fortaleza e litoral leste de Caucaia.

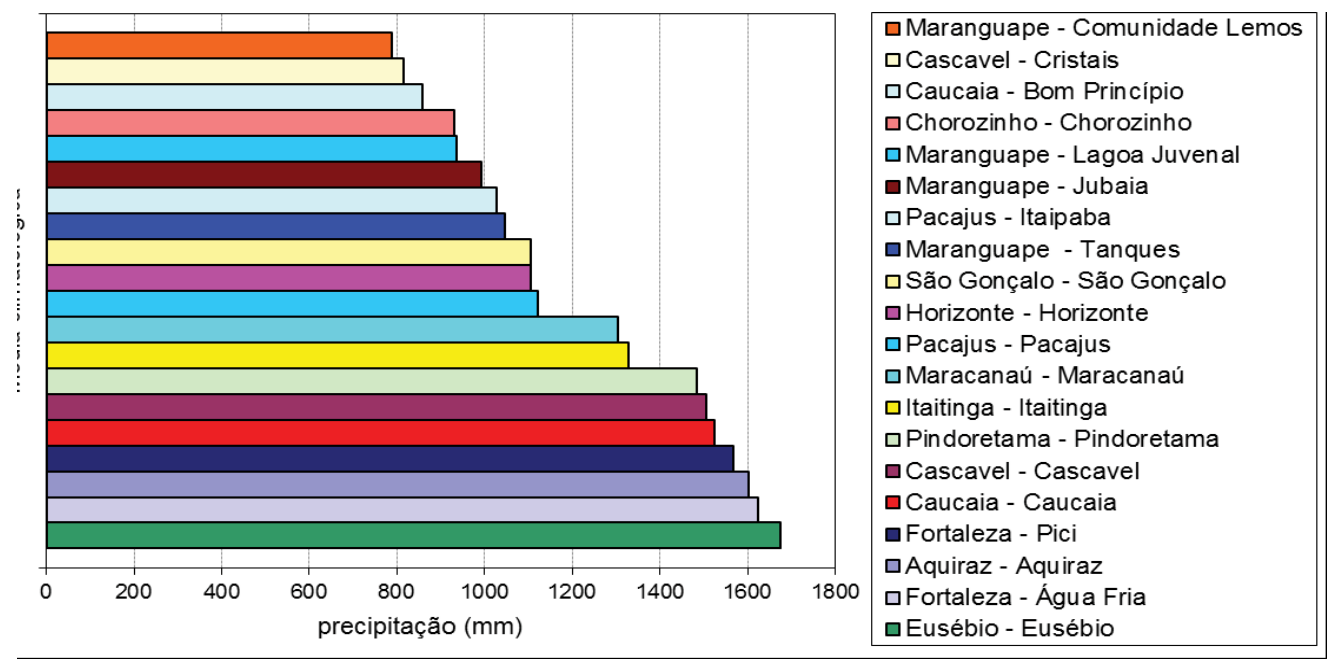

Figura 1 - Gráfico da Média Climatológica dos Postos Pluviométricos da RMF

A quadra chuvosa representa $74,68 \%$ das precipitações para o período em estudo o que evidencia a concentração de chuvas nesses quatro meses, cujo mês de abril apresentou o total pluviométrico mais elevado para toda a série e o mês de outubro o menor.

A característica basilar da precipitação na RMF entre os anos de 2001 a 2009 refere-se ao ritmo sazonal de chuva caracterizado por período seco no inverno e concentração de chuva no verão/outono resultado dos mecanismos de circulação atmosférica geradores de chuva no Nordeste. Estes mecanismos regionais garantem um comportamento anual similar da precipitação para a região. Observando os dados pluviométricos, verificou-se em cada ano um crescimento gradativo da precipitação a partir do mês de fevereiro (com raras exceções como o mês de janeiro do ano de 2004), tendo seu pico no mês de abril e decrescendo nos meses de maio e junho. Todavia o regime pluviométrico é bastante variável, podendo ocorrer anos de chuvas excessivas, como o ano de 2009, e anos com chuvas escassas como o de 2005. Barão de Studart em sua obra "Climatologia epidemias e endemias do Ceará", ao comparar as chuvas de Fortaleza, Quixeramobim e Quixadá dos anos de 1894 a 1898, observou essa irregularidade espacial e temporal das chuvas. Conforme Studart (1909: 16), "de umas e outras se vê como as chuvas variam de um para outro ano e no mesmo ano de uma para outra localidade". 


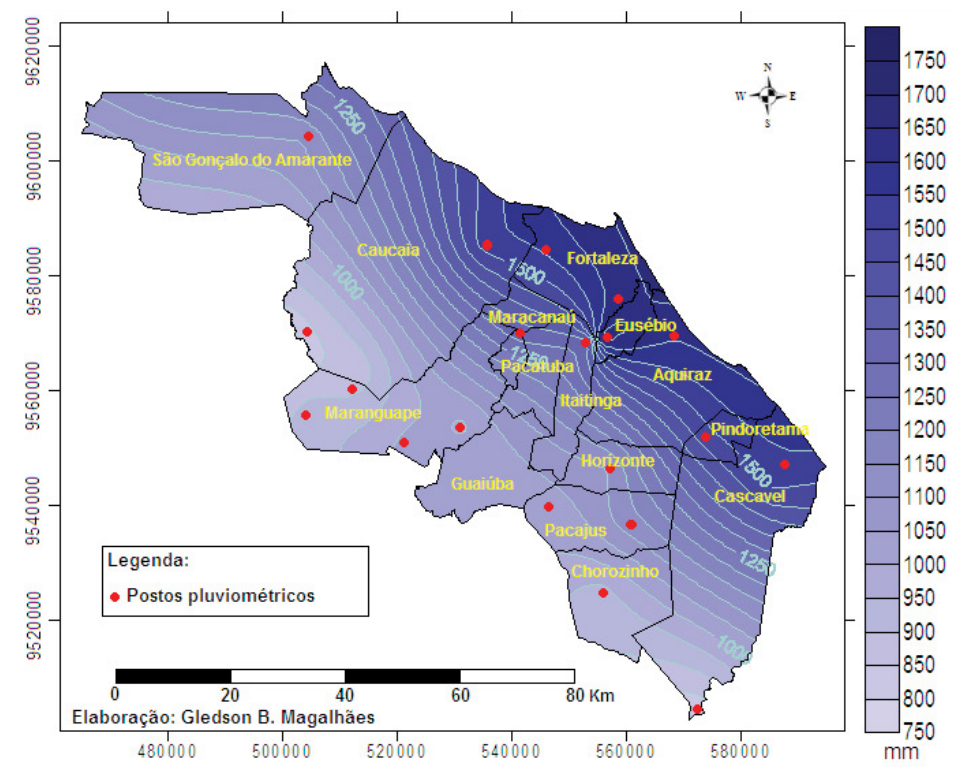

Figura 2 - Isoietas da média climatológica da precipitação pluvial - 2001 a 2009

Por meio do mapeamento dos dados de chuva da RMF para a quadra chuvosa e para o ano correspondente (Figuras 3 a 11) pode-se observar que a espacialização segue um padrão de comportamento. Verifica-se uma predominância de maiores valores de precipitação na faixa litorânea da RMF, diminuindo os totais pluviométricos à medida que se afasta do litoral. Sendo na porção leste do litoral da RMF onde se verificam os maiores registros de precipitação devido à repercussão de sistemas causadores de precipitação provenientes de sistemas atuantes na faixa litorânea dos estados nordestinos a sudeste do Ceará, sejam associados com a ZCIT ou não.

No ano de 2001 a quadra chuvosa representou $77,62 \%$ das precipitações, com mês de abril sendo o mais chuvoso e o mês de outubro o mais seco. Apresentou média pluviométrica de 758,59 $\mathrm{mm}$ na quadra chuvosa registrando maior precipitação no posto Eusébio-Eusébio (1259mm) e menor precipitação no posto Maranguape - Comunidade Lemos $(415 \mathrm{~mm})$, tendo uma diferença de $844 \mathrm{~mm}$ entre os extremos. Para o referido ano, as chuvas tiveram picos de concentração no município de Eusébio, abarcando o setor noroeste de Aquiraz (Figuras 3A e 3B). Doze postos pluviométricos apresentaram chuvas abaixo da normal, quatro apresentaram chuva acima da normal e quatro registraram pluviometria habitual (Quadro 2). Os postos que apresentaram registros inferiores ao normal localizam-se mais ao interior do continente do que os postos que apresentaram normalidade e chuvas acima do normal, exceto o posto de São Gonçalo do Amarante, que mesmo fazendo parte da região pluviometrica homogênea Litoral 2 (Litoral de Pecém) apresentou chuvas abaixo do normal, mostrando um padrão de espacialização da chuva bem condizente com os da média climatológica.

Para toda a RMF, no ano de 2002, a espacialização das chuvas ocorreu de forma mais homogênea que o ano de 2001. A concentração pluviométrica na quadra chuvosa também foi abaixo da de 2001, correspondendo a $67,26 \%$ do total de precipitação do ano, apesar de nesse ano as chuvas terem sido maiores que a do ano anterior, mostrando que as chuvas de 2002 foram mais homogêneas temporo-espacialmente (Figuras 4A e 4B). Como consequência, os postos pluviométricos também apresentaram certa homogeneidade, se comparada ao ano anterior. Quatro postos registraram totais pluviométricos abaixo da normal, sete apresentaram-se acima do habitual e onze tiveram normalidade em seus registros (Quadro 2). As maiores precipitações da quadra chuvosa foram verificadas no posto Cascavel - Cascavel $(1239 \mathrm{~mm})$ e a menor no posto Caucaia - Bom Princípio (495mm), possuindo uma diferença de $744 \mathrm{~mm}$ entre os postos. O posto com mais chuvas foi o posto de Eusébio - Eusébio com 1868,1 mm e o de menor total de chuva permaneceu o posto da quadra chuvosa com $748 \mathrm{~mm}$, possuindo 1120,1 $\mathrm{mm}$ de diferença pluviométrica entre esses dois postos. Os meses 
mais e menos chuvosos foram abril e setembro respectivamente.
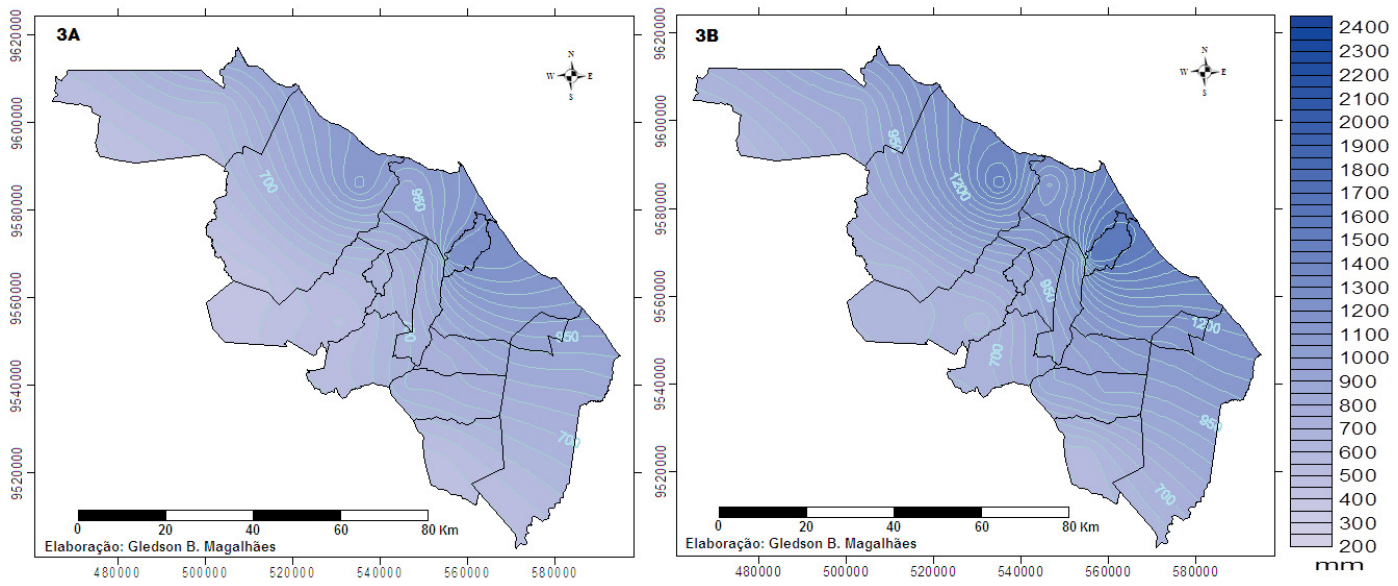

Figura 3 (A e B) - Distribuição da precipitação da quadra chuvosa (3A) e no ano de 2001
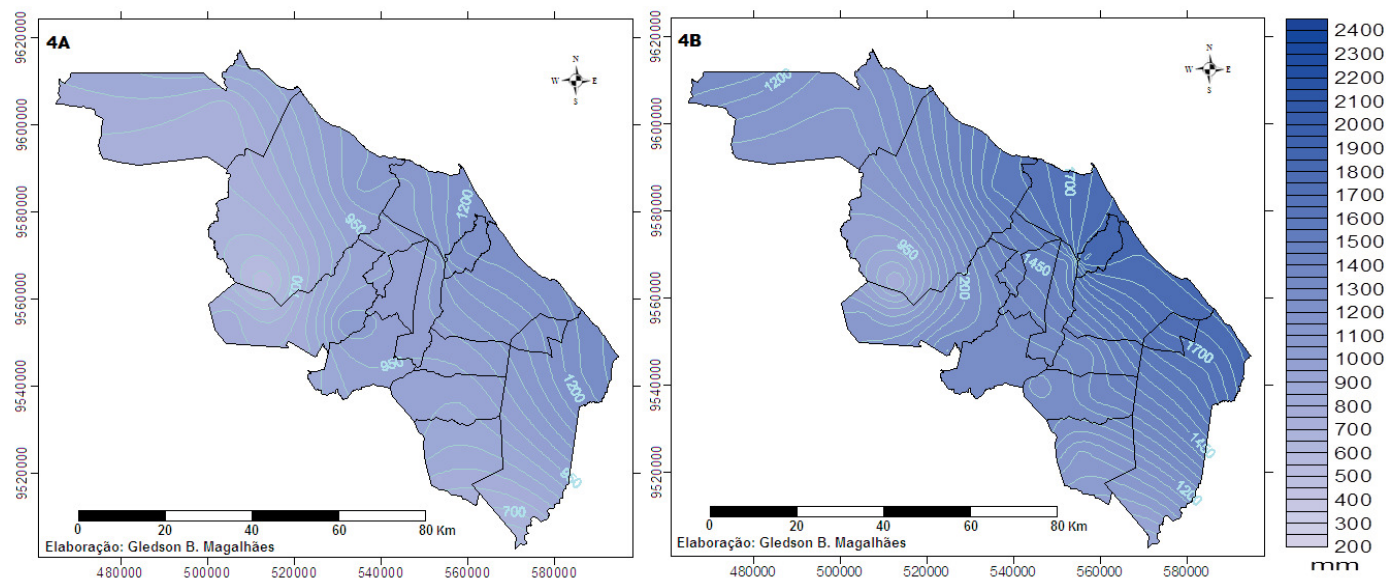

Figura 4 (A e B) - Distribuição da precipitação da quadra chuvosa (4A) e no ano de 2002 (4B)

O ano de 2003 teve no posto de Caucaia - Caucaia o maior total pluviométrico (2277,6 mm), enquanto o menor foi o posto Cascavel - Cristais $(746,8 \mathrm{~mm})$, registrando uma diferença de 1530,8 $\mathrm{mm}$ entre os postos supracitados, sendo o mês de maio e outubro o mais e menos chuvoso respectivamente. Na quadra chuvosa os postos com maiores totais pluviométricos registrados foram os mesmos referentes ao ano, com $1262,8 \mathrm{~mm}$ para o de maior registro e $602,4 \mathrm{~mm}$ para o de menor, tendo uma diferença de $660,4 \mathrm{~mm}$. As chuvas nesse período corresponderam a $80,1 \%$ do total anual. De 2001 a 2003 os totais anuais da quadra chuvosa foram crescentes, sendo o mês de maio e outubro o mais e menos chuvoso respectivamente. Em 2003 foram verificados quatro postos abaixo do habitual, cinco postos com totais pluviométricos habituais e onze postos acima da normal (Quadro 2). Ao contrário dos anos anteriores que tiveram concentração de chuva em Eusébio, os totais de chuva do ano de 2003 foram no município de Caucaia, abarcando a porção nordeste deste município. Os meses de fevereiro a maio apresentaram uma distribuição pluviométrica similar a anual, logicamente com totais pluviométricos menores. As chuvas foram maiores por quase todo o litoral da RMF, indo desde o extremo leste de Cascavel até o nordeste de Caucaia, ultrapassando a isoieta de $1600 \mathrm{~mm}$ anuais, enquanto que a porção mais continental marcou entre 900 a $1200 \mathrm{~mm}$ anuais (Figuras 5A e 5B). 

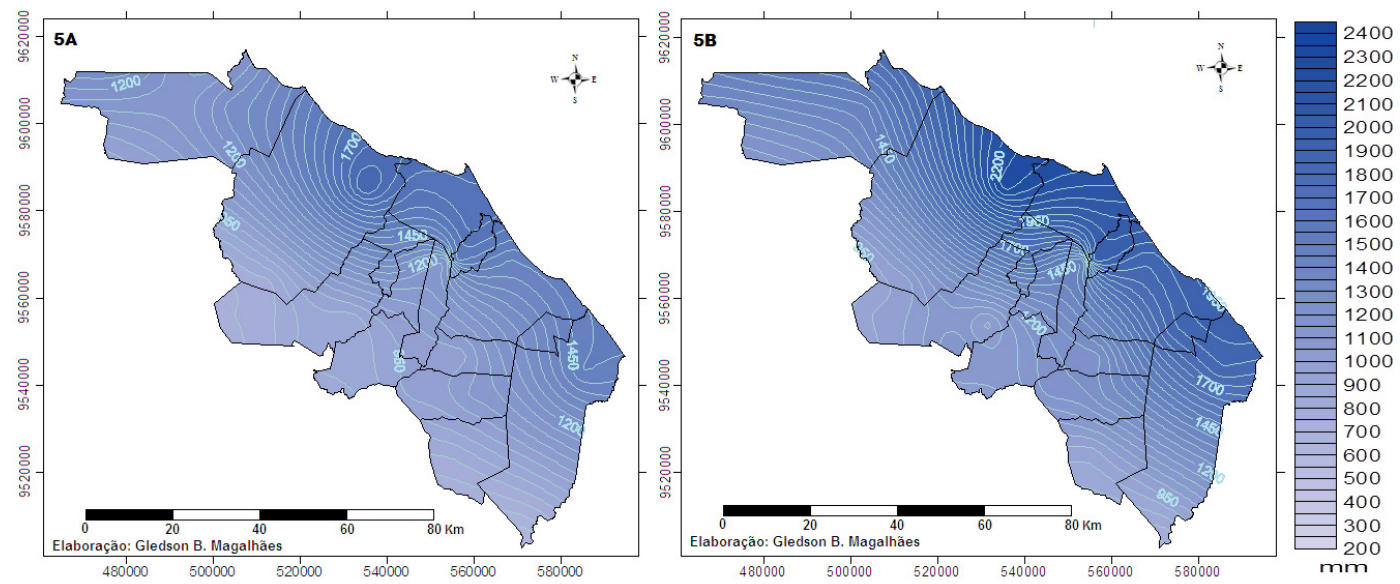

Figura 5 (A e B) - Distribuição da precipitação da quadra chuvosa (5A) e no ano de 2003 (5B)

A menor concentração de chuva na quadra chuvosa foi no ano de 2004 (54,25\%). Registraram-se significativas precipitações no mês de janeiro, junho e julho, prolongando o período chuvoso entre esses meses, caracterizando, assim, um ano atípico. O maior total pluviométrico mensal ocorreu em janeiro, não correspondendo a nenhum mês da quadra chuvosa, e o mês menos chuvoso foi outubro. Este foi o único ano dentro da série analisada que o mês de maior precipitação não correspondeu a quadra chuvosa. Ao se analisar os postos pluviométricos, observou-se uma diferença de 706,4 mm entre o posto de maior (Fortaleza - Água Fria com 1109,4 mm) e menor precipitação (Maranguape - Comunidade Lemos com $444 \mathrm{~mm}$ ) referente ao período chuvoso. Considerando o total de precipitação anual dos postos onde foram identificados os extremos de totais pluviométricos observou-se uma diferença de $1232,7 \mathrm{~mm}$ entre o posto Fortaleza - Água Fria $(2048,7 \mathrm{~mm})$ e o posto Maranguape - Comunidade Lemos $(816 \mathrm{~mm})$. Apesar de as chuvas terem se distribuído como maior equivalência entre os meses do primeiro semestre, se comparada aos anos anteriores, esse ano apresentou muitos postos com precipitação abaixo da normal (13 postos). Isso se deve ao método utilizado, visto que ele considera somente os quatro meses da quadra chuvosa para caracterizar o ano como muito seco, seco, habitual, chuvoso ou muito chuvoso. As precipitações registradas em sete postos enquadram-se como normais e nenhum posto apresentou precipitação acima do habitual, encerrando a tendência crescente de chuva que durou de 2001 a 2003. As chuvas, tanto considerando sua espacialização na quadra chuvosa como no total anual, tiveram maior concentração no litoral da região leste de Cascavel se estendendo até o oeste do litoral de Fortaleza, com picos de chuva no município de Eusébio (Figuras 6A e 6B).
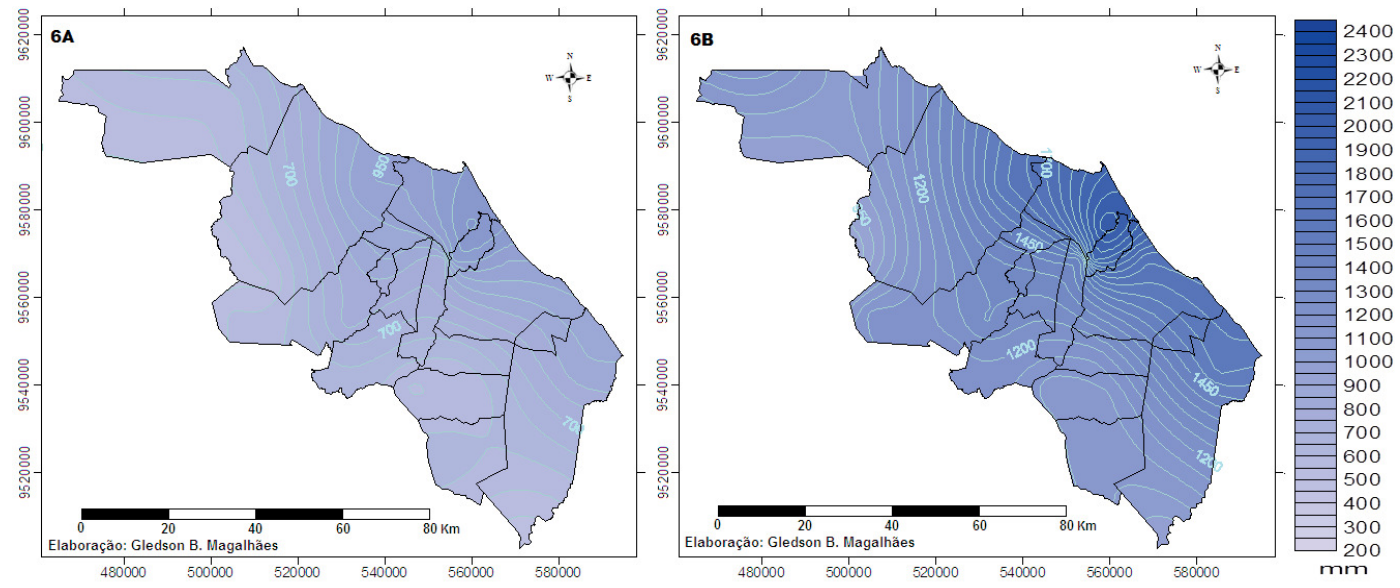

Figura 6 (A e B) - Distribuição da precipitação da quadra chuvosa (6A) e no ano de 2004 (6B) 
O ano de 2005 concentrou $79,68 \%$ de chuvas na quadra chuvosa, tendo maio como mês mais chuvoso, sendo o mês de outubro desse ano o único mês de toda a série estudada que não se registrou nenhuma precipitação. Este ano apresentou menores totais pluviométricos de toda a série estudada, com dezoitos postos apresentando chuvas abaixo do normal e dois com chuvas habituais. $\mathrm{Na}$ quadra chuvosa observou-se uma diferença de $477 \mathrm{~mm}$ entre o posto com mais chuvas (Posto Fortaleza-Pici com $880 \mathrm{~mm}$ ) e o posto com o menor registro (Posto Maranguape - Comunidade Lemos com $403 \mathrm{~mm}$ ). Referente aos totais pluviométricos anuais teve-se uma amplitude pluviométrica de $651 \mathrm{~mm}$ entre os postos de maior registro (Posto Fortaleza - Pici com $1095 \mathrm{~mm}$ ) e o posto com o menor (Posto Maranguape - Comunidade Lemos com $444 \mathrm{~mm}$ ), com picos de chuva em Pindoretama e Fortaleza, marcando isoietas acima de $800 \mathrm{~mm}$ na quadra chuvosa e $950 \mathrm{~mm}$ anuais (Figura 7A e 7B).
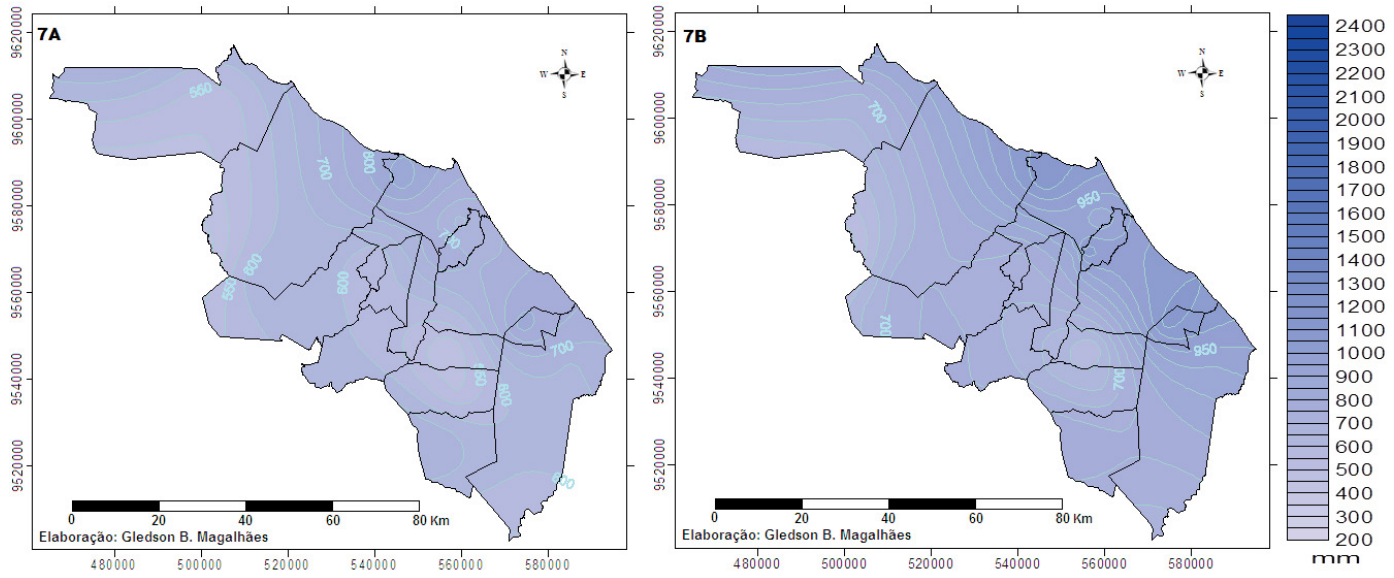

Figura 7 (A e B) - Distribuição da precipitação da quadra chuvosa (7A) e no ano de 2005 (7B)

No ano de 2006 verificou-se uma concentração pluviométrica de $82 \%$ na quadra chuvosa, tendo como mês mais e menos chuvoso respectivamente Abril e Novembro. Seis postos apresentaram totais de chuva acima da normal, dez postos com chuvas habituais e quatro com totais de chuvas abaixo do normal. As amplitudes pluviométricas registradas entre os postos com maior e menor registro para a quadra chuvosa correspondem a $565 \mathrm{~mm}$ entre os postos Cascavel - Cascavel (1252,9 $\mathrm{mm})$ e Maranguape - Lagoa do Juvenal $(687 \mathrm{~mm})$. A amplitude pluviométrica anual foi de 693,1 mm entre os postos de Aquiraz - Aquiraz (1500,6 m) e Cascavel - Cristais (807 mm). O comportamento espacial da chuva foi bem similar ao ano de 2005, se concentrando no litoral leste da RMF, marcando os maiores limiares de chuva no município de Eusébio, e diminuindo a medida que adentra ao continente e a oeste da zona litorânea (Figuras 8A e 8B).
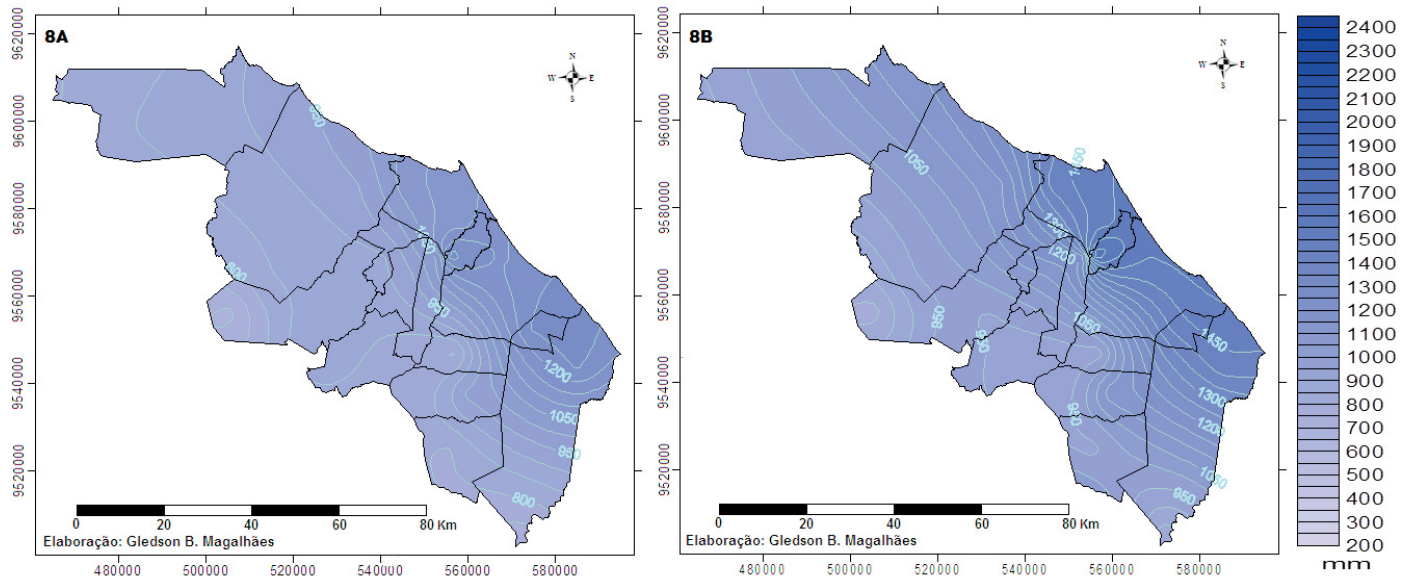

Figura 8 (A e B) - Distribuição da precipitação da quadra chuvosa (8A) e no ano de 2006 (8B) 
Em 2007 ocorreu a maior concentração de chuva na quadra chuvosa da série estudada (91,98\%). A diferença de precipitação entre os postos na quadra chuvosa marcou para os extremos $611 \mathrm{~mm}$ sendo o posto Eusébio - Eusébio o de maior precipitação $(1153 \mathrm{~mm})$ e o posto Maranguape Lagoa do Juvenal o de menor $(542 \mathrm{~mm})$. Referente ao total anual verificou-se uma diferença de 753,5 mm entre o posto de maior registro de precipitação (Eusébio - Eusébio com $1414 \mathrm{~mm}$ ) e o posto de menor registro (Cascavel - Cristais com 660,5 mm). O mês menos chuvoso foi outubro e o maior abril. Dez postos apresentaram registros abaixo do habitual, oito apresentaram totais de chuva normal e dois tiveram acima do habitual, conseqüencia da menor quantidade de chuva se comparado com os anos adjacentes. As chuvas na quadra chuvosa como a anual tiveram uma espacialização similar, haja vista a significativa concentração de chuva entre os meses de fevereiro e maio. A precipitação teve maior concentração no extremo leste da RMF, abarcando o litoral de Cascavel, apesar de nesse município ter o posto com menor total de precipitação na quadra chuvosa, ressalta-se que este posto se localiza no extremo oeste do município. Cascavel, devido a sua área latitudinal ser a mais extensa adentrando o continente, é onde se verifica as maiores diferenças de chuva intra-municipal. Isoietas acima de $1200 \mathrm{~mm}$ anuais marcaram o município de Fortaleza e Eusébio, diminuindo à medida que se afasta do litoral (Figuras 9A e 9B).
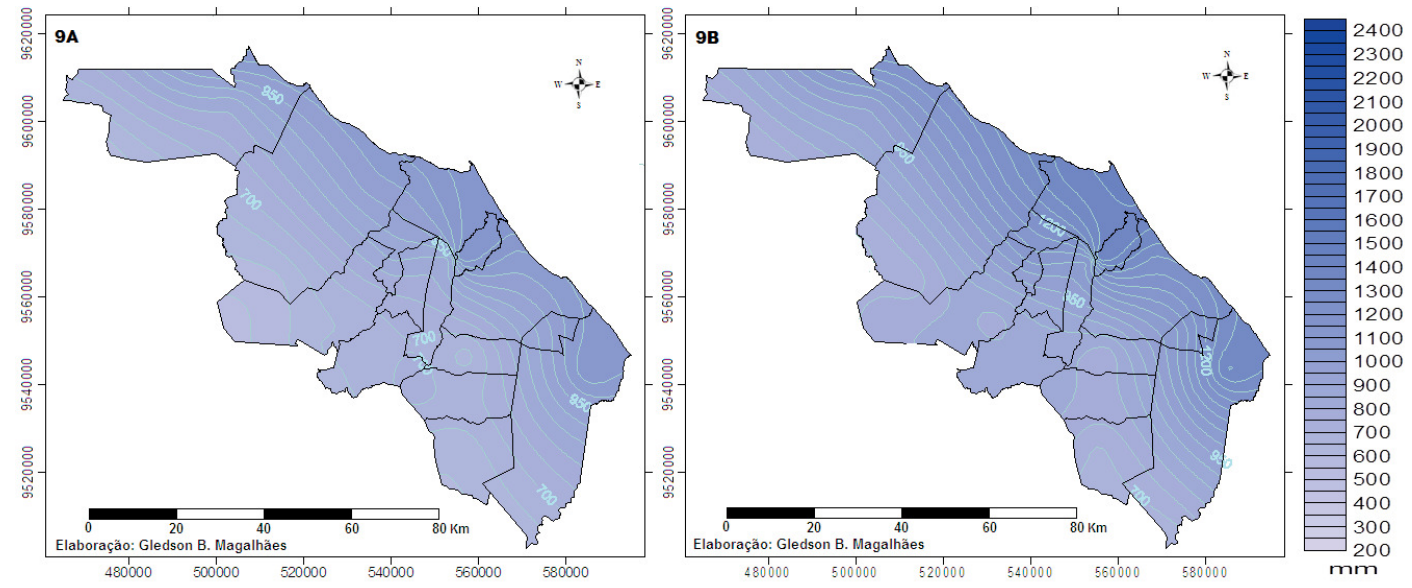

Figura 9 (A e B) - Distribuição da precipitação da quadra chuvosa (9A) e no ano de 2007 (9B)

A precipitação anual volta a subir em 2008, todavia não apresenta um total significativamente acima do total de chuva do ano anterior. Apresenta oitos postos com chuvas abaixo do habitual, dez postos com total normal de chuvas e dois postos acima do habitual. Os meses mais e menos chuvosos são abril e setembro respectivamente, concentrando $79,2 \%$ entre fevereiro e maio. Os postos com Aquiraz - Aquiraz (1182,6 mm) e Maranguape - Comunidade Lemos (460 mm) marcam os totais de precipitação encontrados na quadra chuvosa, tendo uma diferença de $722,6 \mathrm{~mm}$, enquanto que o total de chuva anual tem os limites correspondendo aos mesmos postos $(1563,5 \mathrm{~mm}$ a maior e 604 a menor) com a diferença de $959,5 \mathrm{~mm}$. As chuvas tiverem uma maior distribuição ao longo da faixa litorânea se comparada com os anos anteriores, o município de Aquiraz concentrou signicativa precipitação anual marcando para seu litoral isoietas acima de $1450 \mathrm{~mm}$ anuais (Figuras 10A e 10B). 

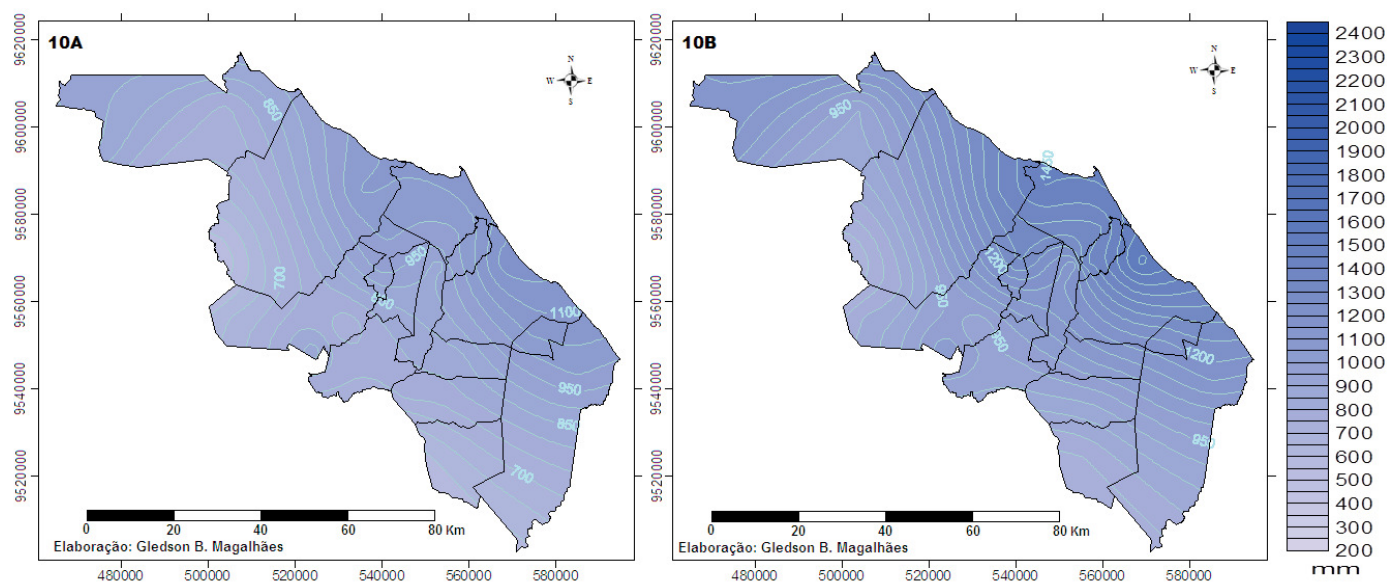

Figura 10 (A e B) - Distribuição da precipitação da quadra chuvosa (10A) e no ano de 2008 (10B)

Para o ano de 2009 o posto Cascavel - Cascavel teve o maior registro de precipitação anual $(2533 \mathrm{~mm})$ enquanto o menor foi no posto Caucaia - Bom Princípio (1114 mm), apresentando, uma diferença de $1419 \mathrm{~mm}$ entre os extremos. Na quadra chuvosa os postos Aquiraz - Aquiraz $(1620,4 \mathrm{~mm})$ e Caucaia - Bom Principio $(915 \mathrm{~mm})$ apresentaram os limites pluviométricos tendo uma diferença de precipitação de 705,4 mm. A quadra chuvosa concentrou 75,17\% da precipitação sendo os meses de abril e novembro os de maior e menor precipitação respectivamente. Este ano foi o ano com o maior total de precipitação entre os anos estudados. Não apresentou nenhum posto com totais de chuva abaixo do normal, cinco postos com chuvas habituais e quinze com chuvas acima do normal. Assim como no ano anterior, o litoral do município de Aquiraz teve as maiores precipitações. Em termos proporcionais e comparando com os anos anteriores, as chuvas que são maiores no litoral, adentraram o continente abarcando a área continental adjacente ao litoral, mostrando que em anos chuvosos, como o de 2009, as chuvas, que em situações normais ou de seca são mais significativas no litoral, tem uma homogeneidade espacial maior (Figuras 11A e 11B).
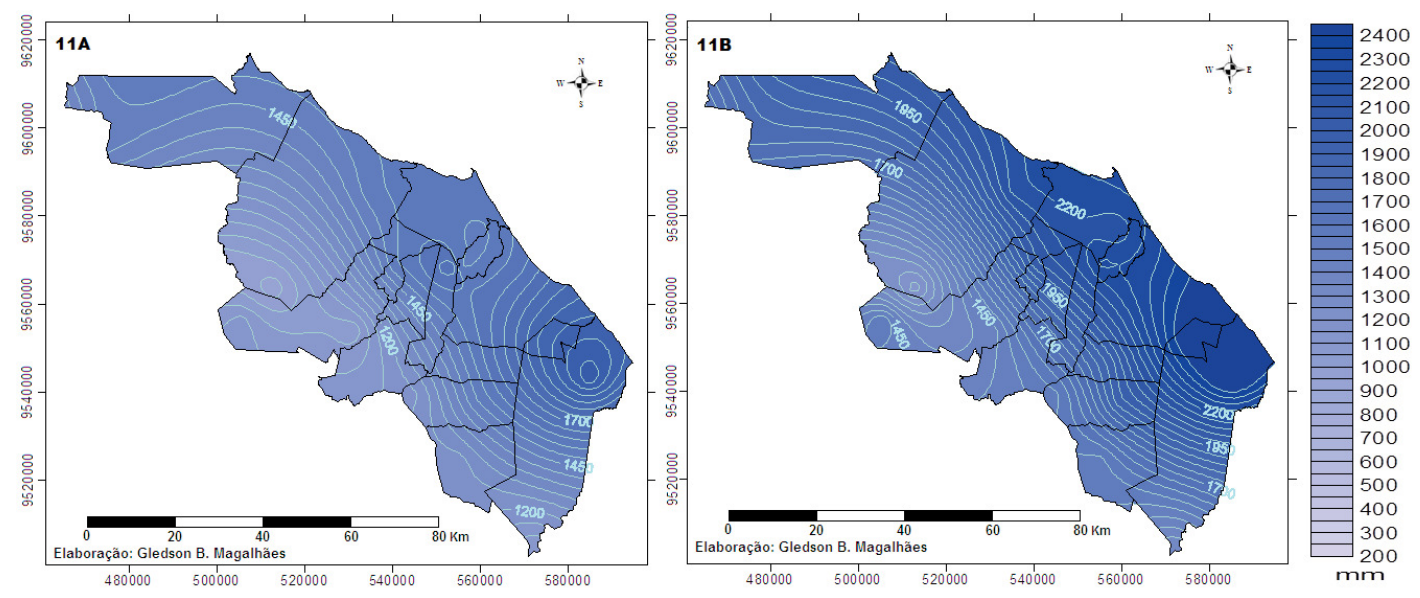

Figura 11 (A e B) - Distribuição da precipitação da quadra chuvosa (11A) e no ano de 2009 (11B)

\section{ANÁLISE DA TEMPERATURA DO AR}

A variação de altitude entre os pontos de estimativa apresentou um papel secundário, haja vista as baixas altitudes dos pontos selecionados. O ponto de maior altitude foi o Posto Maranguape Jubaia com 190 metros. Esse ponto teve as menores temperaturas médias entre todos os pontos para os meses de junho a dezembro. 
Foram verificadas variações de temperatura do ar na ordem de $1,3{ }^{\circ} \mathrm{C}$ (julho e novembro) até $3,2{ }^{\circ} \mathrm{C}$ (abril), entre os pontos verificados. As maiores temperaturas ocorreram nos meses de dezembro e janeiro $\left(28\right.$ e $28,1{ }^{\circ} \mathrm{C}$ respectivamente) e as menores nos meses de junho e julho $(25,4$ e $24{ }^{\circ} \mathrm{C}$ respectivamente). A diferença térmica mensal entre os pontos no mês de dezembro foi de $1,5^{\circ} \mathrm{C}$ sendo a maior temperatura estimada no posto Cascavel - Cristais $\left(28^{\circ} \mathrm{C}\right)$ e a menor no posto Maranguape - Jubaia $\left(26,5^{\circ} \mathrm{C}\right)$. Para o mês de janeiro verificou-se uma diferença de $2,5^{\circ} \mathrm{C}$ entre o ponto com maior temperatura do ar estimada (Posto Cascavel - Cristais com $28,1^{\circ} \mathrm{C}$ ) e o posto com menor temperatura do ar (Maranguape - Jubaia com $26,7^{\circ} \mathrm{C}$ ). Junho e julho tiveram uma diferença térmica de 1,2 e $1,3{ }^{\circ} \mathrm{C}$ respectivamente. A maior temperatura no mês de junho foi verificada nos postos Caucaia - Caucaia e Fortaleza - Água Fria ambos com $26,6^{\circ} \mathrm{C}$, e a menor no posto Maranguape - Jubaia com $25,4{ }^{\circ} \mathrm{C}$. No mês de julho a maior temperatura foi estimada no posto Cascavel - Cristais $\left(26,2^{\circ} \mathrm{C}\right)$ e a menor no posto Maranguape - Jubaia $\left(25^{\circ} \mathrm{C}\right)$

O Posto Cascavel - Cristais foi o ponto onde se verificou o número de meses com os valores mais elevados de temperatura do ar (11 meses). Enquanto o posto Maranguape - Jubaia apresentou em todos os meses as menores temperaturas.

A figura 12 apresenta as flutuações de temperatura do ar ao longo dos meses para os pontos correspondentes aos postos pluviométricos. Nota-se um padrão de comportamento da temperatura ao longo do ano, onde ela decresce no primeiro semestre, tendo as menores temperaturas em julho, no segundo semestre a temperatura do ar se eleva alcançando em seu ápice no mês de dezembro.

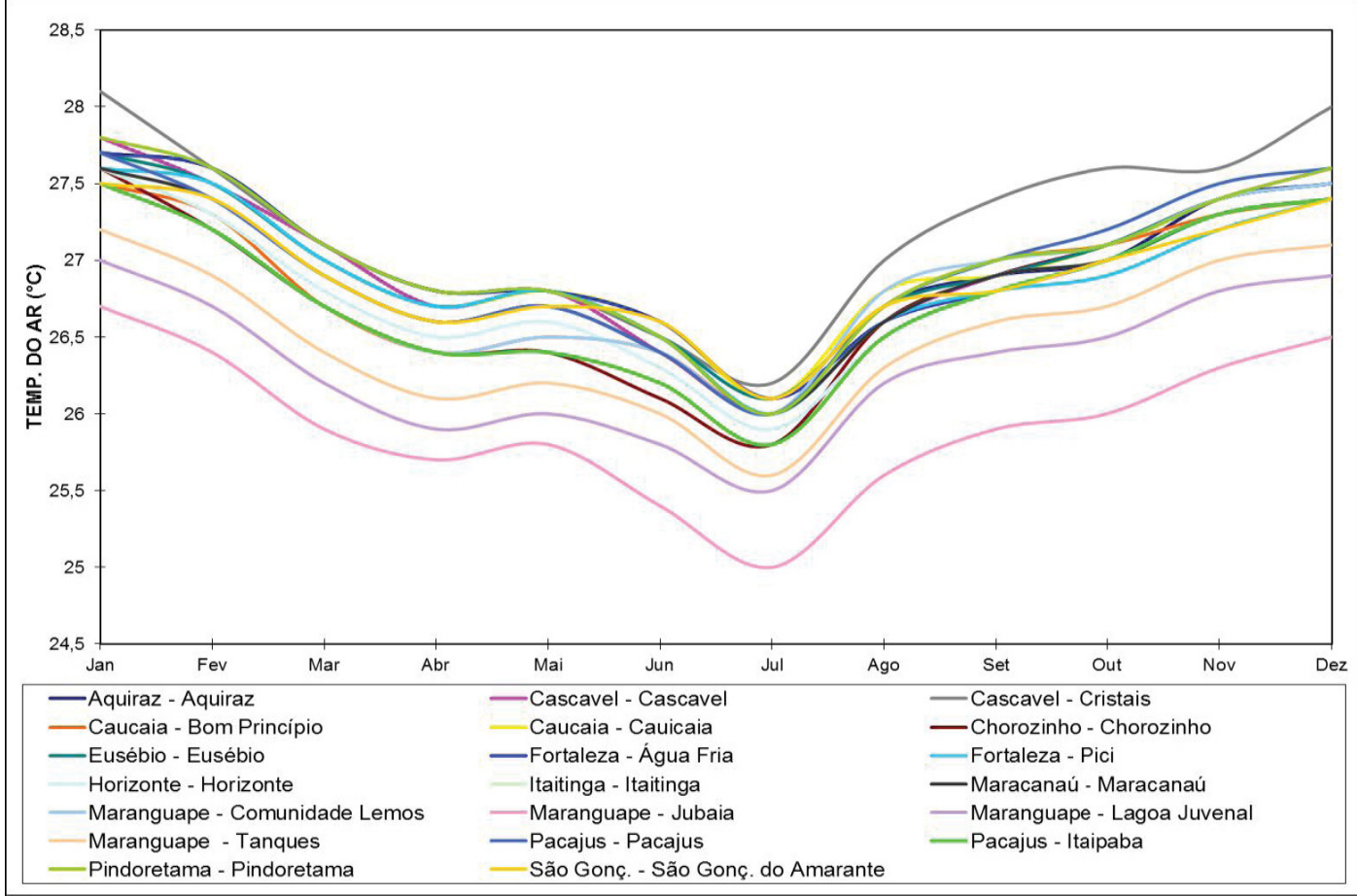

Figura 12 - Gráfico das flutuações de temperatura média mensal ao longo dos meses

Analisando os mapas de isotermas para a RMF (Figuras 13A e 13B) na estação chuvosa e fora dela, verifica-se que há o predomínio de menores médias de temperatura na porção central da RMF.

$\mathrm{Na}$ quadra chuvosa as maiores médias de temperaturas do ar foram verificadas no litoral da RMF englobando boa parte do território dos municípios litorâneos e adentrando o município de Cascavel registrando temperaturas acima de $27^{\circ} \mathrm{C}$. As menores temperaturas concentraram-se nos municípios de Maracanaú, com temperaturas entre 24 e $25^{\circ} \mathrm{C}$, seguidos de Pacatuba, Maranguape e setor sudeste de Caucaia, com temperaturas entre 25 e $26,5^{\circ} \mathrm{C}$, sendo proporcionadas pela influência 
das serras de Maranguape e Pacatuba, que agem como barlavento para as nuvens de baixa altitude proporcionando precipitações orográficas, assim como ventos adiabáticos.

Fora da estação chuvosa as maiores temperaturas (acima de $27^{\circ} \mathrm{C}$ ) foram verificadas na porção sul de Cascavel e em um pequeno setor a sudoeste de São Gonçalo do Amarante. As menores médias de temperatura do ar (entre 25 e $26,5^{\circ} \mathrm{C}$ ) tiveram uma espacialização mais abrangente na quadra chuvosa, influenciados pelo relevo local e pelas precipitações entre os meses de fevereiro a maio, todavia neste período foi estimado as maiores temperaturas do ar (a partir de $27^{\circ} \mathrm{C}$ ) na maior parte do litoral.

Comparando as figuras 13A e 13B, observa-se que as temperaturas mais elevadas tiveram uma expressão maior sob o território da RMF na estação chuvosa, período que corresponde ao verão, caracterizado por temperaturas mais elevadas e maiores precipitações pluviométricas. A maior diferença térmica na quadra chuvosa deve-se a influência da precipitação e do relevo local, caracterizado por enclaves úmidos (maciços residuais) como a Serra de Maranguape e de Pacatuba. Fora da quadra chuvosa verifica-se uma maior homogeneidade da temperatura do ar, onde na maior parte do território da RMF predomina médias de temperatura de $26,5^{\circ} \mathrm{C}$.
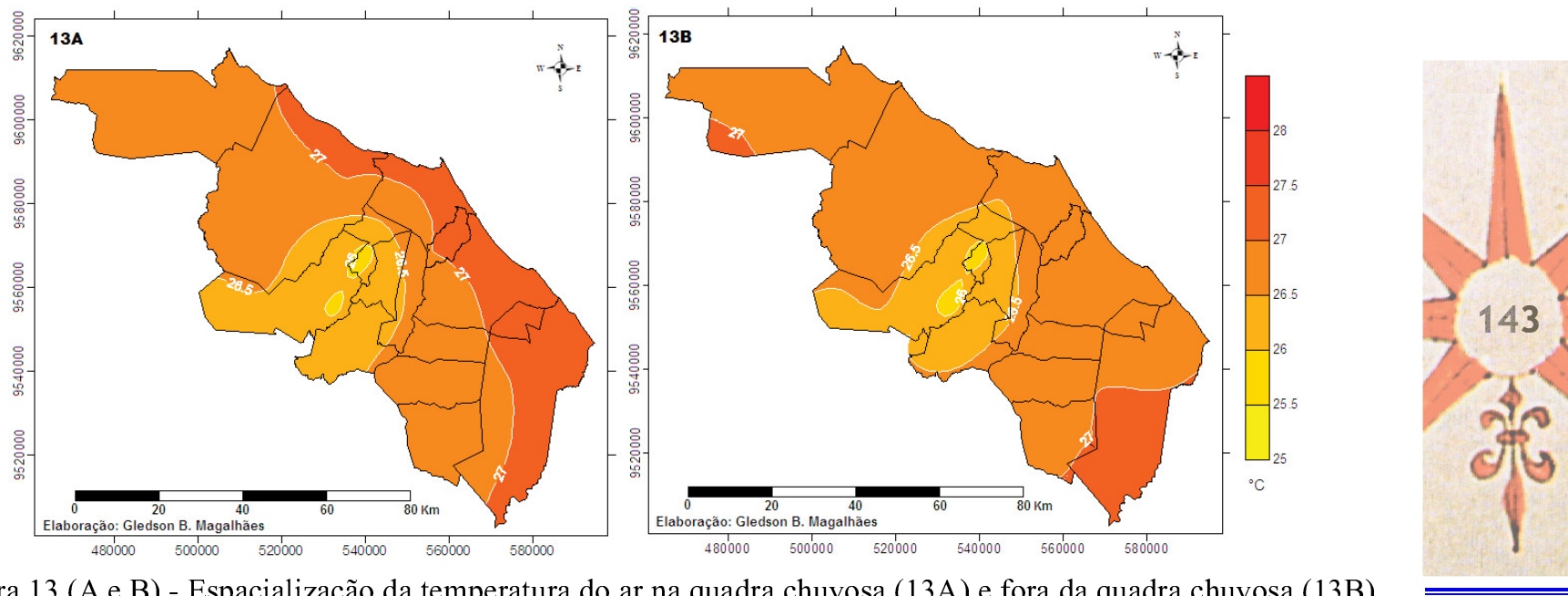

Figura 13 (A e B) - Espacialização da temperatura do ar na quadra chuvosa (13A) e fora da quadra chuvosa (13B)

\section{CONSIDERAÇÕES FINAIS}

O regime pluviométrico mensal das chuvas no período estudado foi sempre o mesmo, com as chuvas concentrando-se no primeiro semestre, e os maiores totais pluviométricos na quadra chuvosa, com os anos muitos chuvosos, como o de 2009, tendo significativas precipitações também nos meses de junho e julho, prolongando o período chuvoso. A irregularidade anual de chuvas na RMF se torna um fator evidente, comprovado pelos desvios anuais observados.

Não se pôde afirmar ocorrer uma ciclicidade de anos chuvosos, todavia percebe-se nitidamente a concentração de chuvas no primeiro semestre do ano, mostrando uma distribuição anual irregular, espacialmente heterogênea, mas nitidamente similar em termos de localização dos totais pluviométricos a cada ano.

A variação espacial da precipitação segue o sentido litoral-continente, comprovando a influência oceânica no aumento da precipitação em áreas mais próximas do litoral. Ressalta-se que as áreas com altitudes mais elevadas como as serras do Pereiro, Maranguape, Pacatuba e do Juá, podem apresentar maiores precipitações, todavia não se pôde comprovar esse fato para os anos em estudo devido a inexistências de dados nessas áreas. Brandão (1998) esboçou um zoneamento pluviométrico para a RMF, dividido em três zonas: a zona predominante abarcando as áreas próximas do litoral, zonas mais secas localizada na porção ocidental, e as zonas de clima localizado, 
nas áreas de altitudes elevadas, onde ocorrem chuvas orográficas que, segundo o autor, "determina um aumento significativo da pluviometria média anual, situando-se numa faixa da ordem de 1.400 -1.600 mm." (p.23).

Podem ocorrer, chuvas excessivas em curtos espaços de tempo, como os episódios de 11 e 21 de abril de 2001 onde se registrou no Posto Pici 124,2 e $102 \mathrm{~mm}$ respectivamente, ou o de 1 de maio de $2006 \mathrm{com} 113 \mathrm{~mm}$ e de forma mais significativa a chuva de $331 \mathrm{~mm}$ (Posto Pici) do dia 29 de janeiro de 2004 ocasionada por um VCAN associado a ZCIT. Estas chuvas e enquadram na categoria de eventos extremos, acarretam sérios problemas as populações submetidas direta e indiretamente as inundações.

As estimativas de temperatura do ar apresentaram pouca variabilidade espacial, com diferença de $2^{\circ}$ entre a menor e a maior, concentrando as baixas temperaturas nas serras e Maranguape e Pacatuba, com médias de $25^{\circ} \mathrm{C}$. Temperaturas mais elevadas foram verificadas nos meses de janeiro e dezembro, e as menores nos meses de junho e julho.

\section{REFERÊNCIA BIBLIOGRÁFICA}

ARAGÃO, J. O.R. Fatos sobre o fenômeno de El Niño e sua relação com as secas no Nordeste do Brasil. Boletim da Sociedade Brasileira de Meteorologia, v. 1, nº 14, p. 2-8, 1990.

ARAGÃO, J. O. R. O impacto do ENSO e do Dipolo do Atlântico no nordeste do Brasil. Bulletin Institut Français Études Andines, v.27, nº 3, p.839-844, 1998.

BRANDÃO, R. L. Sistema de informações para gestão e administração territorial da região metropolitana de Fortaleza - Projeto SINFOR: Diagnóstico geoambiental e os principais problemas de ocupação do meio físico da região metropolitana de Fortaleza. CPRM. 88 p. Fortaleza, Ceará, 1998.

COLARES, J. Q. S. Mapeamento preliminar da região metropolitana de Fortaleza-CE escala 1: 100.000. Dissertação Mestrado. São Paulo. Universidade Estadual Paulista, Instituto de Geociências e Ciências Exatas, Campus de Rio Claro. 1996. 181p.

FERREIRA, F. F.; ALVES, J. M. B.; COSTA, A. A. Um estudo dos impactos das temperaturas da superfície do mar (TSM) em macrorregiões, pluviométricamente homogêneas, no Estado do Ceará. Revista Brasileira de Agrometeorologia, v. 12, $\mathrm{n}^{\circ}$ 1, p. 193-204, 2004.

MAIA, L.P et al. Alterações climáticas na região de Fortaleza causada por fatores naturais e antrópicos. Revista de Geologia UFC. Fortaleza, v. 9, p.111- 121, 1996.

MENDONÇA, F. A. Clima e Criminalidade: ensaio analítico da correlação entre a temperatura do ar e a incidência de criminalidade urbana. Curitiba. Trabalho apresentado à Universidade Federal do Paraná para concurso de Professor Titular, 1999.

MENDONÇA, F.; DANII-OLIVEIRA, I. M. Climatologia: noções básicas e climas do Brasil. São Paulo: Oficina de Texto, 2007.

MONTEIRO,C. A. F. Teoria e Clima Urbano. São Paulo: IGEOC-UPS, 1976.

MONTEIRO,C. A. F. Teoria e Clima Urbano: um projeto e seus caminhos. In: MONTEIRO, C. A. F.; MENDONÇA, F. de A. Clima urbano. São Paulo: CONTEXTO, 2003.

MOURA, B. A. G.; ARAGÃO, J. O. R.; LACERDA, F. F.; PASSAVANTE, J. Z. O. Relação entre a precipitação no setor leste do Nordeste do Brasil e a temperatura da superfície nos oceanos Atlântico (área do Dipolo) e Pacífico. Revista Brasileira de Engenharia Agrícola e Ambiental, v.4, n.2, p.247-251. 2000.

MOURA, M.O. O clima urbano de Fortaleza sob o nível do campo térmico. Dissertação de Mestrado. Fortaleza: UFC - Programa de Pós-graduação em Geografia, 2008. 319 p.

NOBRE, P., and SHUKLA, J., Variations of sea surface temperature, wind stress, and rainfall over the tropical Atlantic and South America. J. Climate, in press, 1996.

PÉTALAS, K.V. Impactos sobre os parâmetros climáticos em duas áreas de Fortaleza-Ce. (Dissertação de Mestrado). Fortaleza: Pós-graduação da Engenharia Civil/UFC, 2000.

STUDART, G. B. de. Climatologia epidemias e endemias do Ceará. ed. fac-sim. Fortaleza: Fundação Waldemar Alcântra, 1997. (Fac.símile da edição publicada em 1909). 
XAVIER, T. de Ma. B.S. Alterações climáticas urbanas em Fortaleza/CE. In: Anais IX Congresso Brasileiro de Meteorologia. Campos do Jordão: SBMET, 1996.

XAVIER, T. de Ma. B.S. Tempo de Chuva - estudos climáticos e de previsão para o Ceará e o Nordeste Setentrional. Fortaleza: ABC Editora, 2001. 478p.

ZANELLA, M. E. As características climáticas e os recursos hídricos do Ceará. In: SILVA, J. B. da.; CAVALCANTE, T. C.; DANTAS. E. W. (orgs.) Ceará: um novo olhar geográfico. Fortaleza: Edições Demócrito Rocha, 2005.

Trabalho enviado em setembro de 2011 Trabalho aceito em outubro de 2011 